University of Wollongong

Research Online

Faculty of Engineering and Information

Faculty of Engineering and Information

Sciences - Papers: Part B

Sciences

2019

Axial-flexural interaction diagram of RPC columns reinforced with steel fibres

Ahmed Al-Tikrite

University of Wollongong, afs017@uowmail.edu.au

Muhammad N. S Hadi

University of Wollongong, mhadi@uow.edu.au

Follow this and additional works at: https://ro.uow.edu.au/eispapers1

Part of the Engineering Commons, and the Science and Technology Studies Commons

Research Online is the open access institutional repository for the University of Wollongong. For further information contact the UOW Library: research-pubs@uow.edu.au 


\title{
Axial-flexural interaction diagram of RPC columns reinforced with steel fibres
}

\begin{abstract}
This paper presents analytical modelling of the axial-flexural behaviour of Reactive Powder Concrete (RPC) columns reinforced with and without steel fibres of different types (industrial and waste) in individual and hybrid forms. An analytical stress-strain model for unconfined RPC was used for the analysis of the axial loads and bending moments of the fibrous RPC columns. The layer-by-layer numerical integration method was used to calculate the axial load and bending moments in this study. The analytically developed axial load-bending moment ( P-M ) interaction diagrams were validated by using experimental results from the literature. A para- metric study was carried out to investigate the influence of the properties of steel fibres on the axial-flexural behaviour of fibrous RPC columns. It was found that the analytical unconfined stress-strain model used in this study well estimates the maximum axial loads and the maximum bending moments of the RPC columns re-inforced with and without different types of steel fibres. Also, the influence of the properties of steel fibres is more pronounced at eccentric and flexural loading
\end{abstract}

\section{Keywords}

interaction, diagram, columns, axial-flexural, fibres, rpc, steel, reinforced

Disciplines

Engineering | Science and Technology Studies

\section{Publication Details}

Al-Tikrite, A. \& Hadi, M. N. S. (2019). Axial-flexural interaction diagram of RPC columns reinforced with steel fibres. Structures, 19 499-506. 


\section{Axial -Flexural Interaction Diagram of RPC Columns Reinforced with Steel Fibres}

Ahmed Al-Tikrite ${ }^{1}$

${ }^{1} \mathrm{PhD}$ Candidate, Structural Engineering, School of Civil, Mining and Environmental Engineering, University of Wollongong, Australia. Email: afs017@uowmail.edu.au Muhammad N. S. Hadi ${ }^{2}$

${ }^{2}$ Assoc. Professor, School of Civil, Mining and Environmental Engineering, University of Wollongong, Australia, Corresponding Author. Email: mhadi@uow.edu.au

\section{Abstract}

This paper presents analytical modelling of the axial-flexural behaviour of Reactive Powder Concrete (RPC) columns reinforced with and without steel fibres of different types (industrial and waste) in individual and hybrid forms. An analytical stress-strain model for unconfined RPC was used for the analysis of the axial loads and bending moments of the fibrous RPC columns. The layer-by-layer numerical integration method was used to calculate the axial load and bending moments in this study. The analytically developed axial load-bending moment $(P$ $M$ ) interaction diagrams were validated by using experimental results from the literature. A parametric study was carried out to investigate the influence of the properties of steel fibres on the axial-flexural behaviour of fibrous RPC columns. It was found that the analytical unconfined stress-strain model used in this study well estimates the maximum axial loads and the maximum bending moments of the RPC columns reinforced with and without different types of steel fibres. Also, the influence of the properties of steel fibres is more pronounced at eccentric and flexural loadings.

Keywords: RPC column; Steel fibre; Maximum axial load; Bending moment; Loading conditions; $P-M$ interaction diagram. 


\section{Introduction}

The interest in the utilization of Ultra-High Strength Concrete (UHSC) in construction is increasing with the continuous development in the construction industry. Specifically, the use of Reactive Powder Concrete (RPC), which is well known for its superior strength and durability [1-5], in structural members such as columns in lower stories is highly desirable. However, the increase in the strength of the concrete is offset by an increase in the brittleness of the concrete [6-8] which may expose the column to a sudden failure without prior notice. As such, concerns may be raised of utilizing such concrete in structural applications and may limit the widespread utilization of RPC especially in seismically active areas. In addition, the use of concrete of superior strength such as RPC in columns requires more confinement which is normally obtained by reducing the spacing of the confining lateral steel reinforcement in the columns. However, the ACI 318-14 design code [9] limits the minimum spacing between the confining helices or ties to $25 \mathrm{~mm}$ to avoid the congestion of the transverse steel reinforcement and to prevent the formation of a separation plane between the concrete core and the concrete cover. Consequently, enhancing the properties of the RPC is essential to overcome the brittleness issue and improve the behaviour of RPC under loading.

The inclusion of steel fibres in the concrete columns is a practical solution to enhance the behaviour of the concrete columns under loading. The role of steel fibres in the concrete inhibits the initiation of the micro cracks that are developed due to either the applied loads or the shrinkage. The fibres also restrain the widening of the macro cracks by bridging the macro cracks until debonding from the concrete paste [10-12]. However, the geometry, content and type of the steel fibres have a significant influence on the properties of the concrete. It was stated that the length, configuration and the content of the steel fibre included in the concrete greatly influence the load carrying capacity, toughness and the post peak behaviour of the concrete [13-16]. Moreover, some researchers explored the influence of combining different 
types of steel fibres to form hybrid steel fibres on the concrete to make use of the role of each fibre in concrete to maximise the benefits of steel fibres included in the concrete. For instance, Kang et al. [17] and Lawler et al. [18] reported that the tensile behaviour of the concrete was effectively enhanced by the inclusion of the hybrid fibres (macro and micro). Lawler et al. [19] and Hadi et al. [20] reported that the combination of micro and macro fibres noticeably enhanced the strength and the toughness of the concrete compared with the concrete that included one type of fibre. It was reported that the inclusion of steel fibres and polypropylene fibres effectively enhanced the tensile strength, maximum strain and flexural behaviour of the concrete. The improvement was attributed to the role of steel fibre in enhancing the strength and to the role of polypropylene in enhancing the ductility of the concrete [21-23]. Moreover, the hybridization of two types of fibre that differ in the modulus of elasticity was reported by Banthia and Sheng [24]. Steel fibres and carbon fibres were hybridized and included in the concrete. Banthia and Sheng [24] stated that steel fibre which has a high modulus of elasticity has enhanced the strength of the concrete while carbon fibres which has a low modulus of elasticity enhanced the toughness of the concrete.

The influence of steel fibre on the axially loaded members such as reinforced RPC columns has been investigated by Hadi and Al-Tikrite [25] and Al-Tikrite and Hadi [26]. It was reported that the inclusion of steel fibres in the reinforced RPC columns has effectively influenced the load carrying capacity and the ductility of the columns. Moreover, the influence of steel fibre on the post peak behaviour was apparent in comparison with non-fibrous columns. Similar findings were reported by Hadi [27], Aoude et al. [28], Aoude et al. [29] and Hosinieh et al. [30]. Nevertheless, the analytical axial load-bending moment interaction diagram of the RPC column reinforced with different types of steel fibres has not been investigated as yet. As such, this study ; as a complementary study for the studies conducted by Hadi and Al-Tikrite [25] and Al-Tikrite and Hadi [26]; investigate analytically the axial load-bending moment $(P-M)$ 
interaction diagrams of the RPC columns that included different types of steel fibre (industrial and waste) in individual and hybrid forms. A stress-strain model for unconfined fibrous RPC was used to construct the $P-M$ interaction diagrams. The experimental investigations of Hadi and Al-Tikrite [25] and Al-Tikrite and Hadi [26] on the behaviour of RPC column reinforced with and without different types of steel fibres tested under concentric, eccentric and flexural loadings was used for validation. Also, the influence of the steel fibres properties such as aspect ratio on the performance of the fibrous RPC columns under different loading conditions is investigated analytically in this research paper.

\section{The (P-M) Interactions Analytical Modelling}

To adequately present the behaviour of the RPC columns analytically in comparison with the experimental results, a proper stress-strain model that takes into account the strength of the concrete and the influence of different types of steel fibre of different geometry and volume content must be applied. Al-Tikrite and Hadi [31] investigated the applicability of applying the existing stress-strain models proposed in the literature on the unconfined RPC reinforced with different types of steel fibre of different types of steel fibre of different geometry and volume content. Al-Tikrite and Hadi [31] concluded that the influence of the properties of steel fibers on the behavior of concrete under compression is not well presented in the models that were proposed in the literature. The applicability of the empirical stress-strain models on the unconfined RPC that included different types of steel fibers of different properties is not adequate. As such, Al-Tikrite and Hadi [31] have proposed a stress-strain model for RPC reinforced with different types of steel fibre of different geometry and volume content. The proposed model used in this study is specifically designed for reactive powder based concrete reinforced with different types of steel fibre of different geometry and volume content where no coarse aggregates is included and the influence of steel fibre are very apparent in the behaviour of this type of concrete (See Fig. 1). Consequently, the axial load-bending moment 

interaction diagrams $(P-M)$ of the RPC columns were developed analytically by applying the stress-strain relationship model for unconfined RPC that was proposed by Al-Tikrite and Hadi [31]. For RPC columns tested under eccentric and flexural loadings, the layer-by-layer numerical integration method was used to analyse the columns' cross section.

For the RPC columns tested under concentric loading, the axial strength of the reinforced RPC column was calculated using the expression given by Eq. 1:

$$
P_{o}=0.85 f_{c}^{\prime}\left(A_{g}-A_{s}\right)+f_{y} A_{s}
$$

where, $P_{o}$ is the nominal axial load, $f_{c}^{\prime}$ is the compressive strength of RPC, $A_{g}$ is the gross area of the column, $A_{s}$ is the area of the longitudinal steel bars and $f_{y}$ is the yield strength of the longitudinal steel reinforcement.

For the RPC columns tested under eccentric and flexural loadings, the cross section was analysed by using the layer-by-layer numerical integration method to predict the total load and the corresponding bending moment. In this method, the cross section is divided into $m$ number of small strips. The height of the small strips is equal to $t$ and the width is equal to $l_{i}$. The height of strips was set to $1 \mathrm{~mm}$. Figure 2 shows the layer-by-layer numerical integration method. The assumptions made were that the plane section remains plane and the strain along the cross section is linear. The concrete strain at the centre of each strip $\left(\varepsilon_{i}\right)$ was assumed to be linearly distributed along the cross section of the columns. The strain in each strip was determined by using the expression given by Eq. 2:

$$
\varepsilon_{c_{i}}=\varepsilon_{u} \frac{\mathrm{d}_{n}-\left(i-\frac{1}{2}\right) \mathrm{t}}{d_{n}}
$$


where, $\varepsilon_{c_{i}}$ is the strain at any concrete strip, $d_{n}$ is the depth of the neutral axis and $\varepsilon_{u}$ is the maximum concrete strain which is normally taken as 0.003 . However, in this study, $\varepsilon_{u}$ that was experimentally obtained has been used in Eq. 2 for all columns.

The stress in each concrete strip was determined by modelling the whole cross section analytically as unconfined cross section using the continuous axial stress-strain curve that was proposed by Al-Tikrite and Hadi [31] as presented as follows:

$$
\begin{array}{rlr}
f_{c_{i}}=f_{c}^{\prime}\left[\frac{\beta x}{(\beta-1)+x^{\beta}}\right] & \varepsilon_{c} \leq \varepsilon_{c o} \\
f_{c_{i}}=f_{c}^{\prime}\left[\frac{n \beta x}{(n \beta-1)+x^{n \beta}}\right] & \varepsilon_{c}>\varepsilon_{c o} \\
\beta & =\left[\frac{1}{1-\frac{f_{c}^{\prime}}{\varepsilon_{c o} E_{i t}}}\right] &
\end{array}
$$

where, $\left(x=\frac{\varepsilon}{\varepsilon_{c o}}\right), f_{c_{i}}$ is the stress in layer $i, f_{c}^{\prime}$ is the compressive strength of the concrete, $\beta$ is a material parameter that depends on the shape of the stress-strain curve, $\varepsilon_{c o}$ is the strain that corresponds to the maximum stress, $E_{i t}$ is the modulus of elasticity of the concrete and $n$ is the descending branch control factor. The descending branch control factor is calculated by using the expression given by Eq. 6:

$$
n=24.487-172 \times 10^{-3}\left(f_{c}^{\prime}+5.96 \frac{V_{f} l_{f}}{\phi}\right)
$$

where, $V_{f}$ is the volume fraction of fibres in percent, $l$ is the length of fibres and $\phi$ is the diameter of fibres.

The strain $\varepsilon_{c o}$ corresponding to the maximum stress and the modulus of elasticity of the concrete $E_{c}$ can be determined by using the expression given by Eq. 7 and Eq. 8, respectively, as follows: 


$$
\varepsilon_{c o}=\left[27 \times 10^{-6}\left(f_{c}^{\prime}\right)-1.4 \times 10^{-6}\left(\frac{V_{f} l_{f}}{\phi}\right)+200 \times 10^{-6}\right]
$$

$$
\left.E_{c}=3.206 \sqrt{f_{c}^{\prime}}+6.9 \quad \quad \text { (in } \mathrm{MPa}\right)
$$

151 152

The force in the mid-height of each layer was calculated by using the expression given by Eq. 9:

$$
P_{c_{i}}=f_{c_{i}} A_{i}
$$

where, $P_{c_{i}}$ is the force at the mid-height of the layer, $f_{i}$ is the stress in the layer and $A_{i}$ is the area of the layer. The bending moment at the mid-height of each layer was calculated by using Eq. 10:

$$
M_{c_{i}}=P_{c_{i}}\left[\frac{D_{0}}{2}-\left(i-\frac{1}{2}\right) \mathrm{t}\right]
$$

where, $M_{c_{i}}$ is the moment in the mid-height of the layer and $D_{0}$ is the outer diameter of the column.

The longitudinal reinforcing bars were placed at a distance of $d_{s_{j}}$ from the extreme compression layer of the column. The strain and stress of each longitudinal bar were determined by using the expressions given by Eq. 11 and Eq. 12:

$$
\begin{aligned}
& \varepsilon_{s_{j}}=\varepsilon_{u} \frac{\mathrm{d}_{n}-\mathrm{d}_{s_{j}}}{d_{n}} \\
& f_{s_{j}}=E_{s_{j}} \varepsilon_{s_{j}} \leq f_{y}
\end{aligned}
$$

where, $\varepsilon_{s_{j}}$ the strain of each longitudinal steel bar, $d_{n}$ is the depth of the neutral axis, $d_{s_{j}}$ is distance between the extreme compressive fibre to the centre of the $j^{\text {th }}$ longitudinal steel bars, $\varepsilon_{u}$ is the maximum concrete strain which is normally taken as 0.003 [32], $f_{s_{j}}$ is the stress in the $j^{\text {th }}$ longitudinal steel bar and $E_{S_{j}}$ is the modulus of elasticity of the $j^{\text {th }}$ steel bar which is $200 \mathrm{GPa}$ and $f_{y}$ is the yield strength of the steel bar. The force that is exerted in each longitudinal reinforcement steel bar was determined by using the expression given by Eq. 13: 


$$
P_{s_{j}}=f_{s_{j}} A_{s_{j}}
$$

172 where, $A_{s_{j}}$ is the cross sectional area of the steel bar.

173

174 The bending moment that was exerted in each longitudinal reinforcement steel bar around the

175 centroid of the columns' circular cross section was determined by using the expression given 176 by Eq. 14:

$$
M_{s_{j}}=P_{s_{j}}\left[\frac{D_{0}}{2}-d_{s_{j}}\right]
$$

In summary, the nominal load $P_{o}$, nominal moment $M_{o}$ and the eccentricity $e$ is obtained as follows:

$$
\begin{gathered}
P_{0}=\sum P_{c_{i}}+\sum P_{s_{j}} \\
M_{0}=\sum M_{c_{i}}+\sum M_{s_{j}} \\
e=\frac{M_{0}}{P_{0}}
\end{gathered}
$$

Moreover, the contribution of the steel fibre in strengthening the concrete in the tension zone was considered in this study. The main parameters of steel fibres that affect the strength of the concrete is the geometrical shape of steel fibres, the tensile stress that the fibre can sustain and the orientation of steel fibres. According to Bentur and Mindess [33], the tensile stress that steel fibre can sustain $\left(\alpha_{f}\right)$ is as follows:

$$
\alpha_{f}=\eta_{\theta_{f}} \tau_{f u} v_{f}\left(\frac{l_{f}}{d_{f}}\right)
$$

where, $\eta_{\theta_{f}}, \tau_{f u}, v_{f}, l_{f}$ and $d_{f}$ are the orientation effectiveness factor, the bond shear strength of the fibre reinforced concrete, steel fibres volume fraction, length of steel fibre and diameter of steel fibre. The bond shear strength of fibre reinforced concrete was calculated as proposed by Marti et al. [34] as follows: 
195

Also, the orientation effectiveness factor $\eta_{\theta_{f}}$ is taken as 0.5 as suggested by Aveston et al. [35] . As such, by considering the behaviour of the longitudinal steel bars as elastic perfectly plastic in the tension and compression zones, the stress in each strip, the maximum load and the corresponding moment can be calculated. A Microsoft EXCEL spreadsheet was designed according to the procedure presented in this paper to calculate the axial loads and bending moments to develop the $P-M$ interaction diagrams.

\section{Summary of the experimental program}

An experimental investigation was conducted by Hadi and Al-Tikrite [25] and Al-Tikrite and Hadi [26] on the steel fibre reinforced RPC column under different loading conditions. Three types of steel fibre were used: micro smooth steel fibre (MF), macro deformed steel fibre (DF) and waste steel fibre recovered from waste tyres (WF). Two types of steel fibre hybridization were conducted: industrial steel fibre hybridization (HF) and waste-industrial steel fibre hybridization (WHF). The plain RPC column (NF) act as a reference column. Twenty four RPC specimens of $200 \mathrm{~mm}$ diameter and $800 \mathrm{~mm}$ length were cast and prepared. Six specimens were tested under concentric, twelve specimens were tested under eccentric and six specimens were tested under flexural loadings. All specimens were reinforced longitudinally with six $12 \mathrm{~mm}$ deformed steel and tied with $10 \mathrm{~mm}$ helix. Figure 3 shows the details of the experimentally tested specimens. Table 1 presents the main test matrix of the experimental work conducted by Hadi and Al-Tikrite [25] and Al-Tikrite and Hadi [26].

\section{Analytical versus Experimental $P$ - $M$ Interaction Diagrams}

To validate the axial load-bending moment interaction diagrams $(P-M)$ that were developed analytically, a comparison was made with the axial load-bending moment interaction diagrams 
that were developed experimentally by Hadi and Al-Tikrite [25] and Al-Tikrite and Hadi [26]. The experimental test results of the RPC specimens tested under concentric, eccentric and flexural loadings are presented in Tables 2 and 3.

The comparison between the analytical and the experimental $P-M$ interaction diagrams is shown in Fig. 4. It is obvious that the analytical model that was proposed by Al-Tikrite and Hadi [31] well matches the $P-M$ interaction diagrams that were obtained experimentally. For Specimens NF-E0, NF-E25 and NF-E50, the analytical maximum axial loads calculated by using Al-Tikrite and Hadi [31] model are $90 \%, 82 \%$ and $77 \%$ of the experimental maximum axial loads. The analytical maximum bending moments corresponding to the maximum axial loads for Specimens NF-25, NF-E50 and NF-PB calculated with Al-Tikrite and Hadi [31] model are $75 \%, 72 \%$ and $66 \%$, respectively, of the experimental maximum bending moments.

The analytical $P-M$ interaction diagrams that were developed using the proposed model of AlTikrite and Hadi [31] have well estimated the axial loads and bending moments of the fibrous RPC columns tested under different loading conditions. For Specimens MF-E0, DF-E0, HFE0, WF-E0 and WHF-E0, the analytical maximum axial loads calculated using the stress-strain model are $88 \%, 84 \%, 89 \%, 86 \%$ and $89 \%$, respectively, of the experimental maximum axial loads.

For the specimens tested under $25 \mathrm{~mm}$ eccentric loading, the analytical maximum axial loads calculated are $88 \%-98 \%$ of the experimental maximum axial loads. The analytical maximum bending moments corresponding to the maximum axial loads are $78 \%-83 \%$ of the experimental maximum bending moments. Moreover, for the specimens tested under $50 \mathrm{~mm}$ eccentric loading, the analytical maximum axial loads calculated are $66 \%-87 \%$ of the experimental maximum axial loads. Also, the analytically calculated maximum bending moments 
corresponding to the maximum axial loads form the stress-strain model are $70 \%-813 \%$ of the experimental maximum bending moments.

Thus, the analytical $P-M$ interaction diagrams developed by using the analytical model proposed by Al-Tikrite and Hadi [31] are found to be in good agreement with the experimental $P-M$ interaction diagrams. In addition, the layer-by-layer numerical integration method is recommended to be used in predicting the axial loads and bending moments of the RPC columns that reinforced with industrial and waste steel fibres.

\section{Parametric Study}

A parametric study was conducted to explore the influence of the geometry of steel fibre in terms of length and diameter of steel fibres on the maximum axial load and maximum bending moment of the RPC columns reinforced with steel fibres tested under concentric, eccentric and flexural loadings. One type of steel fibre which is MF was selected as a representative of steel fibres to investigate the influence of variation in the diameter and length of steel fibre on the maximum load and moment that the column can withstand. As such, MF specimens were used as the reference specimens in the parametric study. The diameters of MF were taken as 0.2 , 0.33, 0.4 and $0.55 \mathrm{~mm}$. The lengths of MF fibres were taken as 10, 18, 26 and $40 \mathrm{~mm}$. The model proposed by Al-Tikrite and Hadi [31] was used for modelling the fibrous RPC column. The layer-by-layer numerical integration method was used for the analysis of the RPC column cross section. The normalised axial load and normalised bending moment were used to construct the $P-M$ interaction diagrams. The normalised axial load and bending moment were calculated according to the analytical expressions given in Eq. 22 and Eq. 23 as follows:

$$
P^{*}=\frac{P}{f_{c o} A_{g}}
$$




$$
M^{*}=\frac{M}{f_{c o} A_{g} D}
$$

270

271

272 for all variations in the diameter, length and volume content in the parametric study. Also, the

273 contribution of the steel fibre in the tension zone has been taken into account to demonstrate

274 the influence of steel fibre in enhancing the strength of the concrete. As a result, the influence

275 fibre. diameter, length and ratio of steel fibres on the axial load and bending moment of the RPC column is shown in Fig. 5. The variation in the diameter of steel fibre has a very slight effect on the axial load and bending moment at eccentric and flexural loadings as shown in Fig. 5 (a). Increasing the diameter of the steel fibres from $0.2 \mathrm{~mm}$ to $0.55 \mathrm{~mm}$ resulted in the axial eccentric load and the corresponding moment was increased significantly. Figure 5 (b) shows that the variation in the length of steel fibre has a significant effect on the load and the corresponding moment under eccentric and flexural loadings. It is apparent that short length steel fibre has more influence on the axial load and the corresponding moment under eccentric loading. Also, the flexural load and bending moment was greatly influenced by short length steel fibres more than long steel fibres. Figure 5 (c) shows that the variation in the percentage of steel fibre has slight influence on the axial load and the corresponding moment of RPC columns in comparison with the influence of the variation in the diameter and length of steel 


\section{Conclusion}

291 This research study reports the experimental and analytical results of the experimental and

292

293

294

295

296

297

298

299

300

301

302 analytical axial load-bending moment interaction diagrams of RPC columns reinforced with and without different types of steel fibres. The following conclusions were drawn based on the experimental and analytical results:

The $P-M$ interaction diagrams were developed analytically based on an analytical model proposed by Al-Tikrite and Hadi [31] have adequately described and well matched the experimental $P-M$ interaction diagrams. The layer-by-layer numerical integration method utilized in this research study can be utilized to precisely calculate the maximum axial loads and the maximum bending moments of the fibrous RPC columns.

The parametric study shows that the variation in the diameter of steel fibre influences the peak load and the corresponding moment of the fibrous RPC column undergoes eccentric loading. Moreover, the variation in the length of steel fibre greatly influences the flexural load and the bending moment of the fibrous RPC column undergoes flexural loading.

Based on the results obtained, the inclusion of the steel fibres in single or hybrid form effectively increased the axial load and the bending moment that RPC columns sustained.

\section{Acknowledgement}

The authors would like to express their gratitude to the technical officers in the Laboratory of Civil, Mining and Environmental Engineering department of the University of Wollongong, Australia for their assistance in laboratory work. Also, the first author would like to acknowledge the Iraqi Government and University of Wollongong, Australia for the full support for his $\mathrm{PhD}$ scholarship. 


\section{References}

316 [1] P. Richard, M.H. Cheyrezy, Reactive powder concretes with high ductility and 200-800

317 MPa compressive strength, Special Publication 144 (1994) 507-518.

[2] M. Zhang, V. Shim, G. Lu, C. Chew, Resistance of high-strength concrete to projectile impact, International Journal of Impact Engineering 31(7) (2005) 825-841.

[3] Y. Tai, Flat ended projectile penetrating ultra-high strength concrete plate target, Theoretical and Applied Fracture Mechanics 51(2) (2009) 117-128.

[4] A. Al-Tikrite, M.N.S. Hadi, Mechanical properties of reactive powder concrete containing industrial and waste steel fibres at different ratios under compression, Construction and

324 Building Materials 154 (2017) 1024-1034.

[5] M.N.S. Hadi, A.H. Algburi, M.N. Sheikh, A.T. Carrigan, Axial and flexural behaviour of circular reinforced concrete columns strengthened with reactive powder concrete jacket and fibre reinforced polymer wrapping, Construction and Building Materials 172 (2018) 717-727. [6] D. Cusson, P. Paultre, High-strength concrete columns confined by rectangular ties, Journal of Structural Engineering 120(3) (1994) 783-804.

[7] M. Mansur, M. Chin, T. Wee, Stress-strain relationship of high-strength fiber concrete in compression, Journal of materials in civil engineering 11(1) (1999) 21-29.

[8] P. Paultre, R. Eid, Y. Langlois, Y. Lévesque, Behavior of steel fiber-reinforced highstrength concrete columns under uniaxial compression, Journal of Structural Engineering 136(10) (2010) 1225-1235.

[9] ACI Committee (ACI 318-14), Building code requirements for structural concrete and commentary, ACI, Farmington Hills, United States (2014).

[10] V.C. Li, Y. W. Chan, Determination of interfacial debond mode for fiber-reinforced cementitious composites, Journal of engineering mechanics 120(4) (1994) 707-719.

[11] V.C. Li, H. Stang, Interface property characterization and strengthening mechanisms in fiber reinforced cement based composites, Advanced cement based materials 6(1) (1997) 1-20. 
[12] M. Nili, V. Afroughsabet, Combined effect of silica fume and steel fibers on the impact resistance and mechanical properties of concrete, International journal of impact engineering 37(8) (2010) 879-886.

[13] M.C. Nataraja, N. Dhang, A.P. Gupta, Stress-strain curves for steel-fiber reinforced concrete under compression, Cement and Concrete Composites 21(5-6) (1999) 383-390.

[14] R. Olivito, F. Zuccarello, An experimental study on the tensile strength of steel fiber reinforced concrete, Composites Part B: Engineering 41(3) (2010) 246-255.

[15] Z. Wu, C. Shi, W. He, L. Wu, Effects of steel fiber content and shape on mechanical properties of ultra high performance concrete, Construction and Building Materials 103 (2016) $8-14$.

[16] H. Xia, W. Wang, Z. Shi, Mechanical properties of reactive powder concrete with ultrashort brass-coated steel fibres, Magazine of Concrete Research 67(6) (2015) 308-316.

[17] S. T. Kang, J. I. Choi, K. T. Koh, K.S. Lee, B.Y. Lee, Hybrid effects of steel fiber and microfiber on the tensile behavior of ultra-high performance concrete, Composite Structures 145 (2016) 37-42.

[18] J.S. Lawler, D. Zampini, S.P. Shah, Permeability of cracked hybrid fiber-reinforced mortar under load, Materials Journal 99(4) (2002) 379-385.

[19] J.S. Lawler, D. Zampini, S.P. Shah, Microfiber and macrofiber hybrid fiber-reinforced concrete, Journal of Materials in Civil Engineering 17(5) (2005) 595-604.

[20] M.N.S. Hadi, E.K. Balanji, M.N. Sheikh, Behavior of steel fiber-reinforced high-strength concrete columns under different loads, ACI Structural Journal 114(4) (2017) 815.

[21] D. Feldman, Z. Zheng, Synthetic fibres for fibre concrete composites, MRS Proceedings, Cambridge Univ Press, 1993, p. 123.

[22] M. Glavind, T. Aarre, High-strength concrete with increased fracture-toughness, MRS Proceedings, Cambridge Univ Press, 1990, p. 39. 
[23] E.S. Larsen, H. Krenchel, Durability of FRC-materials, MRS Proceedings, Cambridge

367

368

369

370

371

372

373

374

375

376

377

378

379

380

381

382

383

384

385

386

387

388

389

Univ Press, 1990, p. 119.

[24] N. Banthia, J. Sheng, Micro-reinforced cementitious materials, MRS Proceedings, Cambridge Univ Press, 1990, p. 25.

[25] M.N.S. Hadi, A. Al-Tikrite, Behaviour of fibre-reinforced RPC columns under different loading conditions, Construction and Building Materials 156 (2017) 293-306.

[26] A. Al-Tikrite, M.N.S. Hadi, Influence of Steel Fibres on the Behaviour of RPC Circular Columns Under Different Loading Conditions, Structures, Elsevier, 2018, pp. 111-123.

[27] M.N.S. Hadi, Behaviour of eccentric loading of FRP confined fibre steel reinforced concrete columns, Construction and Building Materials 23(2) (2009) 1102-1108.

[28] H. Aoude, W.D. Cook, D. Mitchell, Behavior of columns constructed with fibers and selfconsolidating concrete, ACI Structural Journal 106(3) (2009) 349.

[29] H. Aoude, M.M. Hosinieh, W.D. Cook, D. Mitchell, Behavior of rectangular columns constructed with SCC and steel fibers, Journal of Structural Engineering 141(8) (2014) 04014191.

[30] M.M. Hosinieh, H. Aoude, W.D. Cook, D. Mitchell, Behavior of ultra-high performance fiber reinforced concrete columns under pure axial loading, Engineering Structures 99 (2015) $388-401$.

[31] A. Al-Tikrite, M.N.S. Hadi, Stress-Strain Relationship of Unconfined RPC Reinforced with Steel Fibers under Compression, Journal of Materials in Civil Engineering 30(10) (2018) 04018234.

[32] A. Bentur, S. Mindess, Fibre reinforced cementitious composites, CRC Press2006.

[33] P. Marti, T. Pfyl, V. Sigrist, T. Ulaga, Harmonized test procedures for steel fiberreinforced concrete, Materials Journal 96(6) (1999) 676-685. 

Testing and Design, 1974, pp. 93-103.

393

394

395

396

397

398

399

400

401

402

403

404

405

406

407

408

409

410

411

412

413

414

415 
417 Table 1. The main test matrix of the experimental investigation.

418 Table 2. Experimental results of columns tested under concentric and eccentric (25 $\mathrm{mm}$ and $41950 \mathrm{~mm}$ ) loading.

420 Table 3. Experimental results of columns tested under flexural loading.

421

422

423

424

425

426

427

428

429

430

431

432

433

434

435

436

437

438

439

440

441 
Table 1. The main test matrix of the experimental investigation.

\begin{tabular}{|c|c|c|c|c|c|}
\hline \multirow[b]{2}{*}{ Group } & \multirow[b]{2}{*}{ Column } & \multirow[b]{2}{*}{ Type of loading } & \multicolumn{2}{|c|}{ Reinforcement } & \multirow[b]{2}{*}{ Steel fibre content } \\
\hline & & & Longitudinal & Transverse & \\
\hline \multirow{4}{*}{ NF } & NF-E0 & Concentric & \multirow{4}{*}{$6 \mathrm{~N} 12$} & \multirow{4}{*}{ R10@40-mm } & \multirow{4}{*}{-} \\
\hline & NF-E25 & Eccentric $25 \mathrm{~mm}$ & & & \\
\hline & NF-E50 & Eccentric $50 \mathrm{~mm}$ & & & \\
\hline & NF-PB & Flexural & & & \\
\hline \multirow{4}{*}{ MF } & MF-E0 & Concentric & \multirow{4}{*}{$6 \mathrm{~N} 12$} & \multirow{4}{*}{ R10@40-mm } & \multirow{4}{*}{$4 \% \mathrm{MF}$} \\
\hline & MF-E25 & Eccentric $25 \mathrm{~mm}$ & & & \\
\hline & MF-E50 & Eccentric $50 \mathrm{~mm}$ & & & \\
\hline & MF-PB & Flexural & & & \\
\hline \multirow{4}{*}{ DF } & DF-E0 & Concentric & \multirow{4}{*}{$6 \mathrm{~N} 12$} & \multirow{4}{*}{ R10@40-mm } & \multirow{4}{*}{$2 \% \mathrm{DF}$} \\
\hline & DF-E25 & Eccentric $25 \mathrm{~mm}$ & & & \\
\hline & DF-E50 & Eccentric $50 \mathrm{~mm}$ & & & \\
\hline & DF-PB & Flexural & & & \\
\hline \multirow{4}{*}{$\mathrm{HF}$} & HF-E0 & Concentric & \multirow{4}{*}{$6 \mathrm{~N} 12$} & \multirow{4}{*}{ R10@40-mm } & \multirow{4}{*}{$2 \% \mathrm{MF}$ and $1 \% \mathrm{DF}$} \\
\hline & HF-E25 & Eccentric $25 \mathrm{~mm}$ & & & \\
\hline & HF-E50 & Eccentric $50 \mathrm{~mm}$ & & & \\
\hline & HF-PB & Flexural & & & \\
\hline \multirow{4}{*}{ WF } & WF-E0 & Concentric & \multirow{4}{*}{$6 \mathrm{~N} 12$} & \multirow{4}{*}{ R10@40-mm } & \multirow{4}{*}{$3 \% \mathrm{WF}$} \\
\hline & WF-E25 & Eccentric $25 \mathrm{~mm}$ & & & \\
\hline & WF-E50 & Eccentric $50 \mathrm{~mm}$ & & & \\
\hline & WF-PB & Flexural & & & \\
\hline \multirow{4}{*}{ WHF } & WHF-E0 & Concentric & \multirow{4}{*}{$6 \mathrm{~N} 12$} & \multirow{4}{*}{ R10@40-mm } & \multirow{4}{*}{$\begin{array}{c}1 \% \mathrm{MF}, 0.5 \% \mathrm{DF} \text { and } \\
1.5 \% \mathrm{WF}\end{array}$} \\
\hline & WHF-E25 & Eccentric $25 \mathrm{~mm}$ & & & \\
\hline & WHF-E50 & Eccentric $50 \mathrm{~mm}$ & & & \\
\hline & WHF-PB & Flexural & & & \\
\hline
\end{tabular}

445 
Table 2. Experimental and analytical results of columns tested under concentric and eccentric (25 mm and $50 \mathrm{~mm})$ loading.

\begin{tabular}{|c|c|c|c|c|c|c|c|}
\hline Group & Column & $\begin{array}{c}\text { Experimental } \\
\text { maximum } \\
\text { axial load } \\
(\mathrm{kN})\end{array}$ & $\begin{array}{c}\text { Analytical } \\
\text { maximum axial } \\
\text { load } \\
(\mathrm{kN}) \\
\end{array}$ & $\begin{array}{c}\text { Experimental } \\
\text { bending moment } \\
(\mathrm{kN} . \mathrm{m})\end{array}$ & $\begin{array}{c}\text { Analytical } \\
\text { bending moment } \\
(\mathrm{kN.m}) \\
\end{array}$ & $\begin{array}{l}\text { Experimental axial } \\
\text { deformation at } \\
\text { maximum axial load } \\
(\mathrm{mm})\end{array}$ & $\begin{array}{l}\text { Experimental lateral } \\
\text { deformation at } \\
\text { maximum axial load } \\
(\mathrm{mm})\end{array}$ \\
\hline \multirow{3}{*}{ NF } & NF-E0 & 3305 & 2967 & - & - & 4.6 & - \\
\hline & NF-E25 & 2194 & 1795 & 59 & 45 & 3.9 & 2.1 \\
\hline & NF-E50 & 1327 & 1028 & 71 & 51 & 6.0 & 3.7 \\
\hline \multirow{3}{*}{ MF } & MF-E0 & 4374 & 3850 & - & - & 5.7 & - \\
\hline & MF-E25 & 2836 & 2483 & 78 & 62 & 4.7 & 2.8 \\
\hline & MF-E50 & 1711 & 1317 & 92 & 66 & 7.8 & 4.2 \\
\hline \multirow{3}{*}{ DF } & DF-E0 & 3608 & 3020 & - & - & 4.9 & - \\
\hline & DF-E25 & 2247 & 1951 & 62 & 49 & 4.0 & 2.7 \\
\hline & DF-E50 & 1414 & 1070 & 76 & 54 & 6.5 & 3.9 \\
\hline \multirow{3}{*}{$\mathrm{HF}$} & HF-E0 & 4055 & 3619 & - & - & 5.1 & - \\
\hline & HF-E25 & 2512 & 2460 & 69 & 61 & 4.7 & 2.8 \\
\hline & HF-E50 & 1529 & 1332 & 82 & 67 & 7.8 & 4.2 \\
\hline \multirow{3}{*}{ WF } & WF-E0 & 4062 & 3510 & - & - & 5.3 & - \\
\hline & WF-E25 & 2496 & 2261 & 69 & 57 & 4.5 & 2.8 \\
\hline & WF-E50 & 1576 & 1037 & 85 & 62 & 7.5 & 4.1 \\
\hline \multirow{3}{*}{ WHF } & WHF-E0 & 4067 & 3602 & - & - & 5.6 & - \\
\hline & WHF-E25 & 2531 & 2347 & 70 & 59 & 4.3 & 2.8 \\
\hline & WHF-E50 & 1516 & 1188 & 81 & 64 & 7.4 & 3.9 \\
\hline
\end{tabular}


Table 3. Experimental results of columns tested under flexural loading.

\begin{tabular}{ccccc}
\hline Group & Column & $\begin{array}{c}\text { Maximum flexural load } \\
(\mathrm{kN})\end{array}$ & $\begin{array}{c}\text { Midspan deflection at maximum axial } \\
\text { load (mm) }\end{array}$ & \multicolumn{2}{c}{$\begin{array}{c}\text { Bending moment } \\
(\mathrm{kN} . \mathrm{m})\end{array}$} \\
\hline NF & NF-PB & 357 & 6.5 & 41 \\
MF & MF-PB & 394 & 7.8 & 44 \\
DF & DF-PB & 379 & 7.6 & 44 \\
HF & HF-PB & 389 & 7.7 & 45 \\
WF & WF-PB & 404 & 8.0 & 47 \\
WHF & WHF-PB & 390 & 7.6 & 45 \\
\hline
\end{tabular}

461 
467 Fig. 1. Stress-strain behaviour of RPC concrete reinforced with different types of steel fibre of 468 different geometry and volume content.

469 Fig. 2. Stress-strain distribution for computing $P-M$ interaction diagram by using layer-by-layer 470 numerical integration method.

471 Fig. 3. Details of the tested RPC specimens.

472 Fig. 4. Analytical versus experimental $P-M$ interaction diagrams of the RPC columns that 473 reinforced with and without steel fibres.

474 Fig. 5. Normalised $P^{*}-M^{*}$ interaction diagrams of the RPC columns: (a) variation in the 475 diameter of steel fibre; (b) variation in the length of steel fibre; (c) variation in the steel fibre 476 ratio.

477 

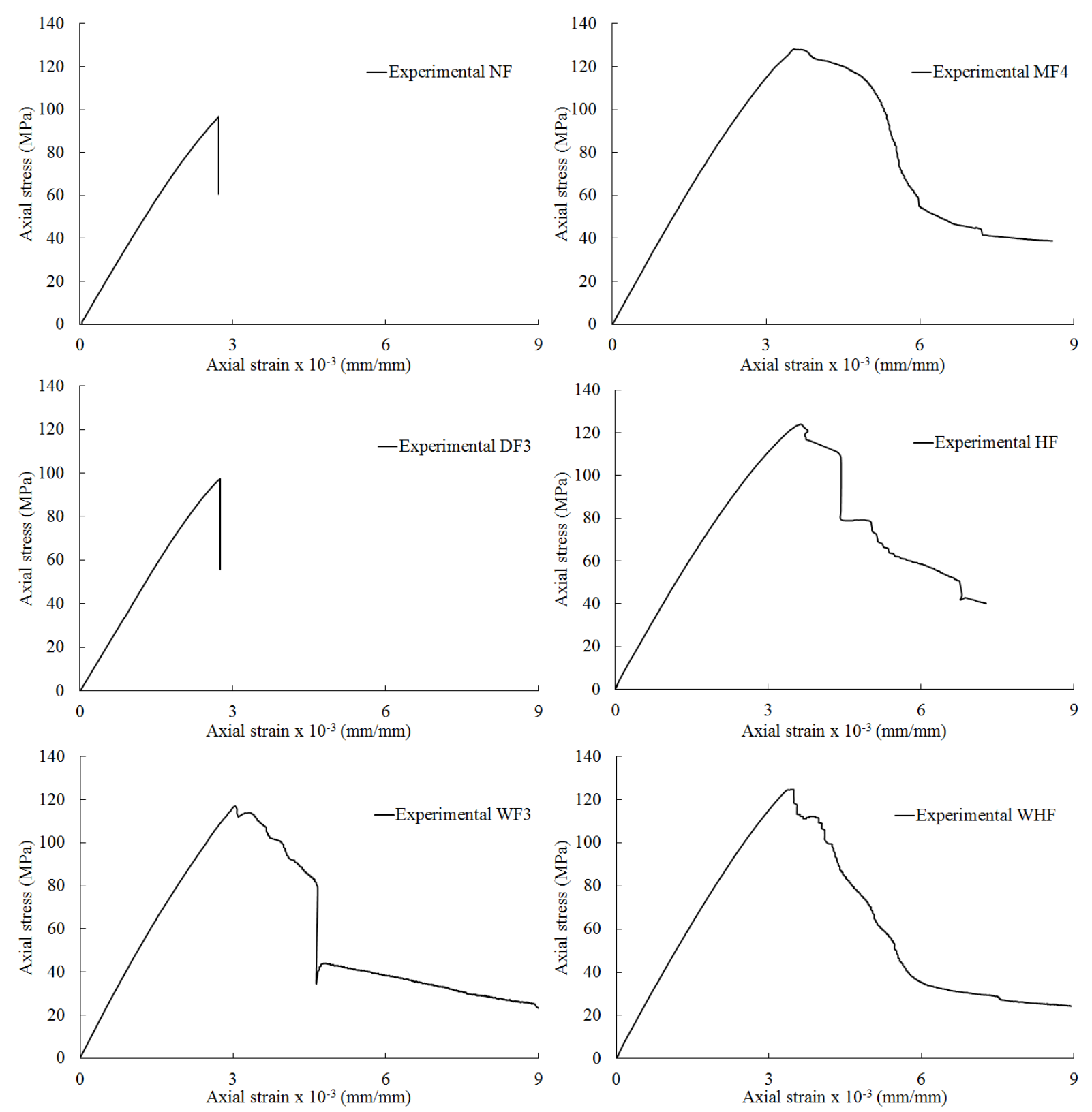

Fig. 1. Stress-strain behaviour of RPC concrete reinforced with different types of steel fibre 


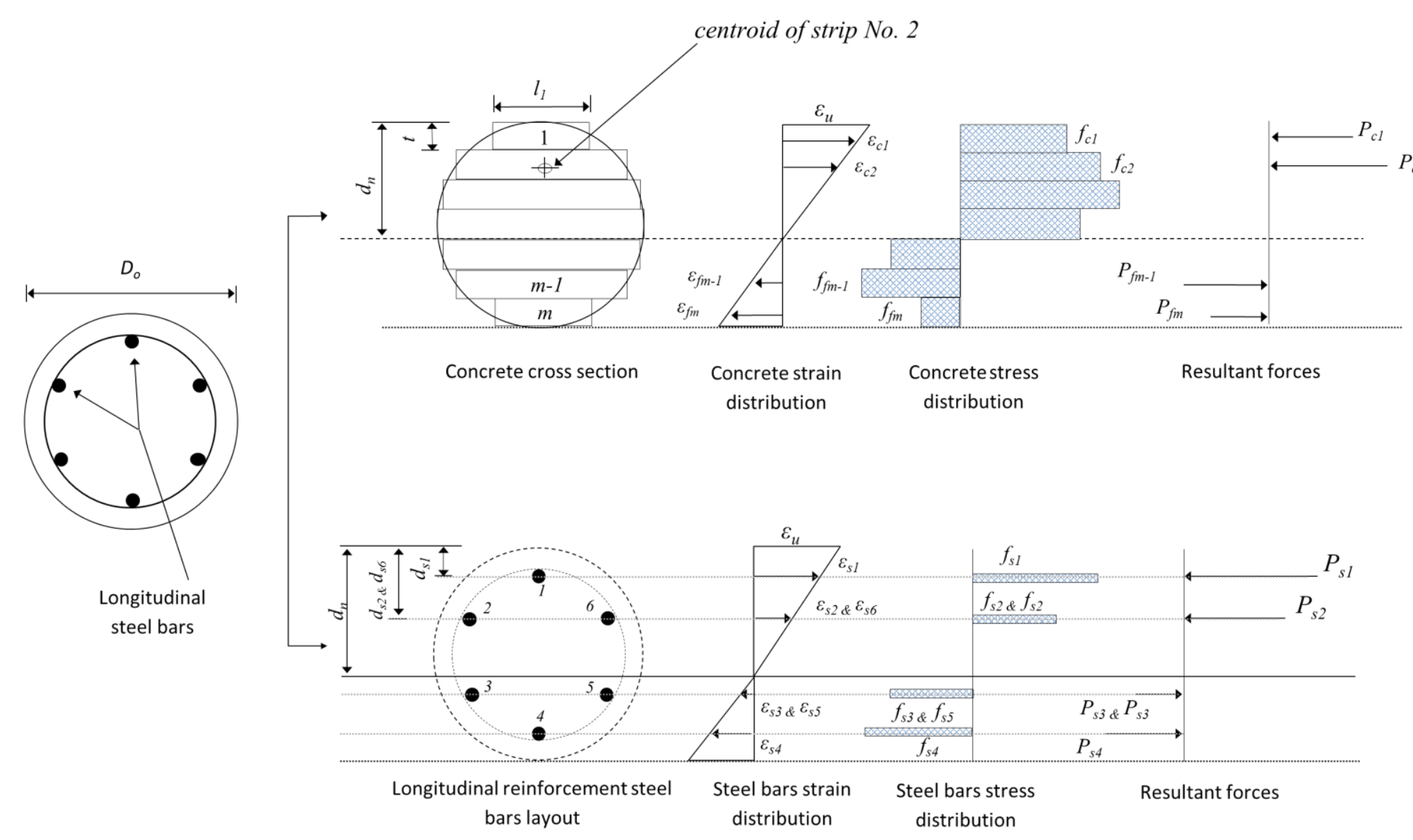

Fig. 2. Stress-strain distribution for computing $P-M$ interaction diagram by using layer-by-layer numerical integration method. 

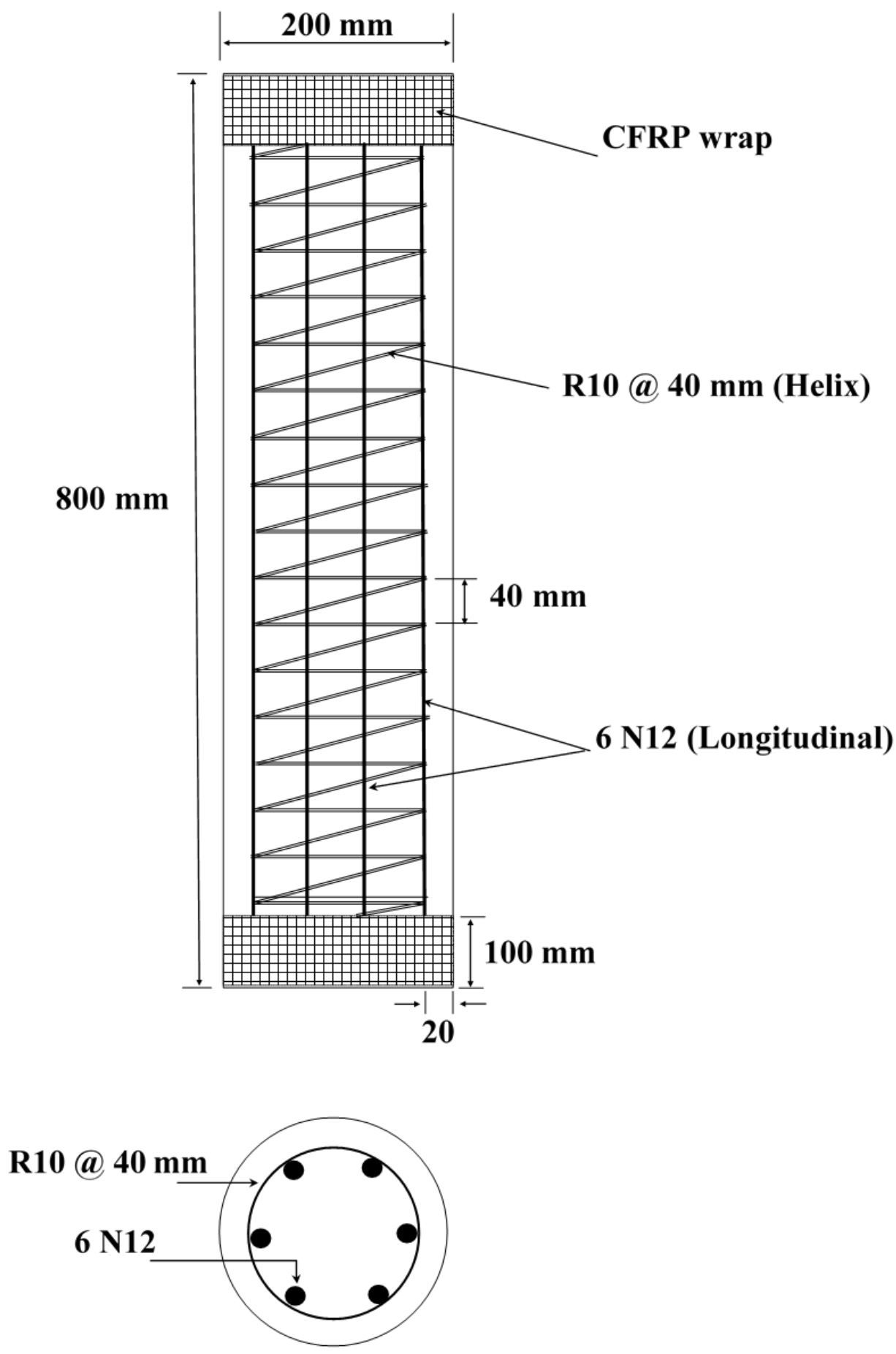

Fig. 3. Details of the tested RPC specimens. 

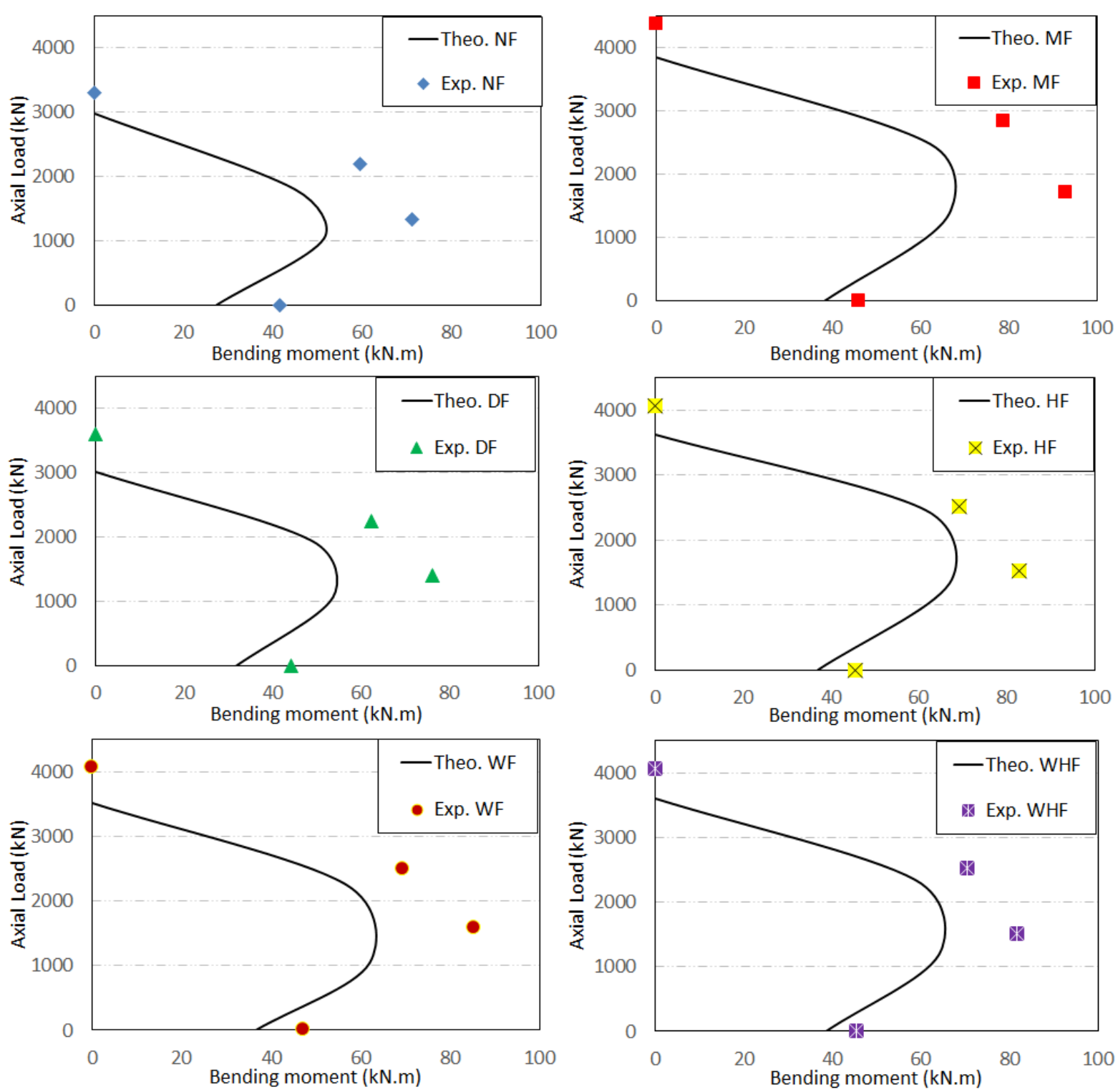

496

Fig. 4. Analytical versus experimental $P-M$ interaction diagrams of the RPC columns reinforced with and without steel fibres. 

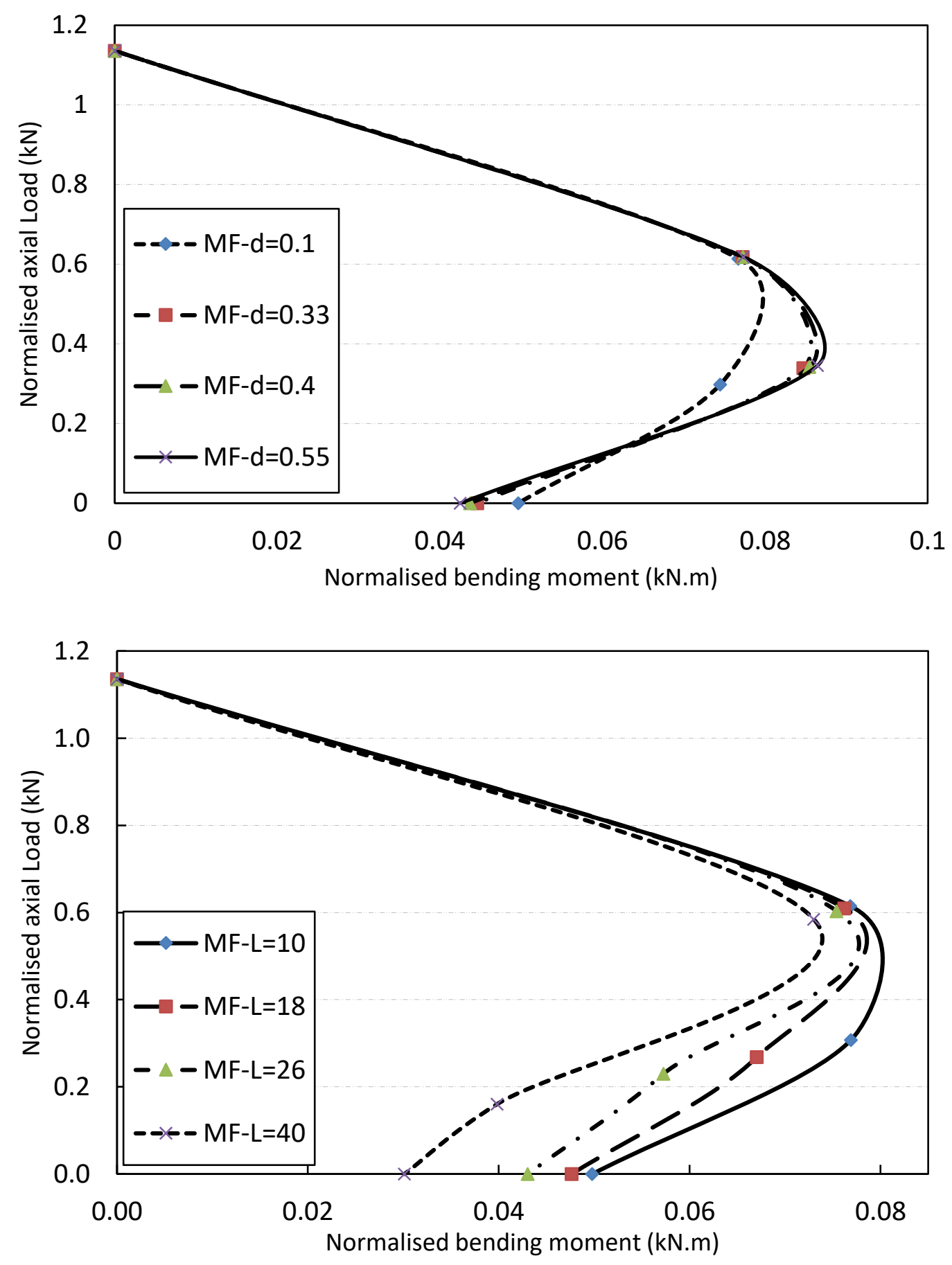


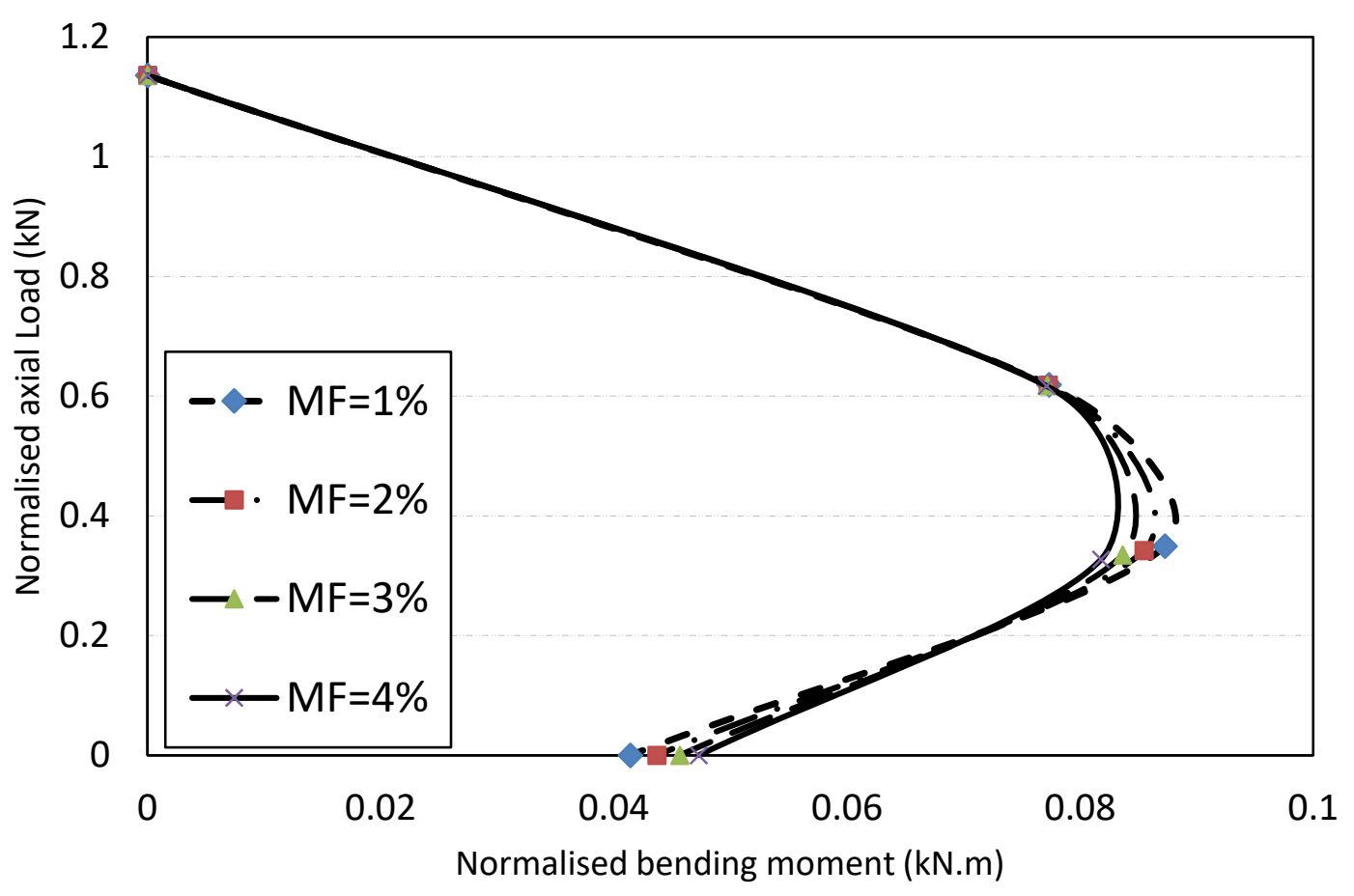

515 Fig. 5. Normalised $P^{*}-M^{*}$ interaction diagrams of the RPC columns: (a) variation in the 516 diameter of steel fibre; (b) variation in the length of steel fibre; (c) variation in the steel fibre ratio. 